\title{
The missing link: Implications of the modernisation theory and the dependency theory in Africa's quest for development.
}

\author{
Primrose Rufaro Mawire \\ Communication Skills Centre, Midlands State University, Zimbabwe
}

\begin{abstract}
The problem of underdevelopment in Africa can neither be underscored nor over-emphasised. As such, Africa's economic, political and social crises have been and continue to be a topical issue. This paper seeks to establish the missing link in Africa's quest for development. African countries are trying to redress the effects of imperialism (a relation of dominance) which produced chronic conditions for perpetual poverty and underdevelopment. This paper argues that development is not purely an economic phenomenon, instead, development must encompass more than the financial and material aspects of life. It (development) must be perceived as a multi-dimensional process involving the re-organisation and re-orientation of entire economic and social systems. The paper also argues that the adoption of the former coloniser's language, for instance, the dominant use of the English language in former British colonies has also been seen to have negative implications on the development of such countries. In other words, when people neglect their traditional structures, language, culture and values, it is tantamount to throwing away their identity, which apparently, impacts negatively on their development. The paper advances the argument by dependent theorists who advocate a 'return to the source' approach, that is, a return to traditional structures and the use of native languages in Africa's quest for development. This is in contrast to the modernisation theory which postulates that developing countries should throw away traditional structures, language, culture and values and emulate Europe and The United States as models for development.
\end{abstract}

\section{Introduction}

This article problematises the modernisation and dependency theories of development as well as well as locating the place and influence that language (be it English or native) has in Africa's quest for development. The strategy which advocated and promoted economic development and modernisation in the newly emergent nation states of Africa, Asia and Latin America (those within the Western Sphere of influence) was formalised in the body of modernisation theory, whereby Nemani (1997) [1] believes that the modernisation theory replicates the nations of Western Europe and the United States as the models of development that newcomers should emulate. Rostow (1960) [2] asserts that the modernisation theory is a transformative society which requires that societies abandon traditional ways of thinking and human relations. In brief, societies must abandon traditional structures, languages, cultures and values and adopt those of Western Europe and North American societies today. Other assumptions conveyed by the modernisation theory are that it is a progressive process which creates 'agonies' for many but that it is 'the right price to pay'. This article seeks to interrogate this stance and evaluate whether indeed it is worthwhile for developing countries to undergo the said 'agonies', which, apparently, include the abandoning of native languages in favour of the former colonisers' languages, in particular, the English language in the case of former British colonies.

In the same breadth and given the failures of the modernisation theory to promote development in the third world, dependency theorists put forward a simple rationale that development and underdevelopment are two sides of the same coin, the advancement of one takes place at the expense of the other. Dependency theory as a theory of underdevelopment emerged in the 1960s under the guidance of the Director of the United Nations Economic Forum, from Latin America, Paul Prebisch. The studies by Prebisch suggested that Economic activities in the richer countries often leads to serious problems in the poor countries. According to Ferraro (1996) [3] the dependency theory rejects the central assumptions of the modernisation theory that Western influence would place poor countries on a path of development similar to that experienced by western industrialised nations. They (dependency theorists) also reject the idea that the modernisation paradigm addresses the problems of poverty and underdevelopment across the world. Senkel (1969:23) [4] defines dependency as "an explanation of the economic development of a state in terms of external influences, political, economic and cultural on national development policies."

This brings us back to the argument that development is not purely an economic phenomenon and that it must encompass more than the financial and material aspects of life, that it requires the re-organisation and re-orientation of entire economic and social systems. The social systems aspect takes us to the issue of the dominant position that the English language holds in former British colonies and how this can have detrimental 
effects on Africa's quest for development. In other words, when people neglect their traditional structures, language, culture and values, it is tantamount to throwing away their identity, which apparently, impacts negatively on their development.

\section{Current Situation}

The current situation as it stands in Zimbabwe is such that the English language is the medium of instruction from grade four right through to University. This has wide implications for success, particularly at tertiary level. What it simply means is that if a student is not proficient in English, they may find it difficult to express their ideas even if they know their subject area well, resulting in that student failing his or her exams, and failing to proceed with his or her studies.

It is also important to note that in Zimbabwe, a former British colony, indigenous languages like Shona used to be taught and examined in English at Advanced Level up to 2005. It was as if it was impossible to teach Shona in Shona at that level. Yet, all languages have a set of speech sounds and they all have rules for putting words together in phrases and sentences. All these languages have words for whatever they want to talk about in their experience. Though at any time, speakers of a certain language may not have words, say for technological gadgets they have never seen or known, As soon as they are introduced to new artefacts and ideas, they immediately acquire appropriate words for them.

\section{Importance Of Language On Development}

The uncontested importance of language in the development of a people is clearly summed up in Salager- Meyer (1994:159)'s [5] assertion that

Language is the source, organizing principle and vehicle for transporting the most important nuclei of symbols and meanings that give rise to thought and human relationships

If indeed language is responsible for giving rise to thought and for human relationships, it probably explains why the coloniser made it a point to foster the dominance of his own language on the colonial subjects, at the expense of their native languages. In a way, it would mean the colonised subjects would think in the manner that the owner of the language would want them to think. And when one reflects on the nature of relationships that existed between the whites and blacks, it was one of dominance of the African people.

By adopting the English language as a medium of instruction in schools, and in universities it meant that the English language was and is still elevated above native languages. By accepting the dominance of the English language over the native languages it is almost tantamount to accepting the superiority of the owner of that language. This may explain why human relationships during the colonial era were characterised by the portrayal of the white man as superior (together with his language) and the African as inferior (together with his language). One can therefore not underestimate the power or influence that a language can have in any society. In that case, African governments should probably consider re-dressing the dominance of the English language as the medium of instruction in schools and in Universities in formerly British colonised African states.

\section{Implications Of Using The English Language}

It is important to take into cognisance the historical events which resulted in the current situation where the English language holds a central position in former British colonies. During the colonial period, Africa was 'othered' by the dominant Western Countries, pitching the European Civilisation ways and language as the only way.

Dos Santos in Fann et-al (1971) [6] believes that the underdevelopment of Africa is a result of a historical condition which shapes certain structures of the world economy such that it favours some countries to the detriment of others and limits the development possibilities of others - a situation in which the economy of a certain group of countries is conditioned by the development and expansion of another economy to which their own is subjected.

Davidson (1992) [7] also tries to locate the problems of Africa in history and specifically, as a result of years of colonialism, where the development of African countries is conditioned by their economic and social relations with the former coloniser. Davidson (1992) [7] asserts that Africa's crisis of society derives from many upsets and conflicts but they all derive from social and political institutions within which decolonised Africans have lived and tried to survive. Primarily, it is a crisis of institution. If indeed the problem of the underdevelopment of Africa is institutionalised, it probably also means that the dominance of the English language in former British colonies is also institutionalised. Apparently, human beings tend to think more creatively in the language in which they are more comfortable, which happens to be their first language or mother tongue. If they are then forced to learn and think in a foreign language it definitely limits their creative abilities, which probably explains why Africa is still struggling to develop today.

Blake (2008) [8] rightly observes that language enables human beings to convey complex information about a variety of topics ranging from "kinship to astronomy" and to pass on such information to the next 
generation, a cumulative process that results in all the wonders of the modern science and technology, in other words, in development. In this case one may be tempted to say that it may be necessary for Africans to develop themselves and to pass on the knowledge to their next generations, in their own language, so as not to limit their thinking and creative abilities.

\section{Way Forward}

It has been established so far that language is crucial to every aspect of people's lives, whether they are thinking or talking. Languages help their users to relate to each other and to the world. There is also a major link between language and identity. Apparently, according to Bowers (1974), [9] an equally important yet not unrelated characteristic of being human is the need to know who they are in the social sense, that humans feel compelled to establish a self- identity and then spend a lifetime trying to maintain it intact against the inroads of biological and social change.

It goes without say that a people's native language plays a pivotal role in establishing their identity. As such it is probably important for former British colonies to go back to the drawing board and reconsider the place of their native languages in their educational policies and to elevate them. Policy has been defined by the Oxford Dictionary as "a course of action adopted by a government, party, ruler or statesman. As such, governments should consider changing education policies and recognise their native languages as medium of instruction in schools and tertiary institutions. In other words, if a student excels in their subject area, and yet are not proficient in English, that should not limit them if they are allowed to express themselves in their native language, which will help in the development of the people and their nation, instead of limiting them simply because they are not proficient in English. In any case, it has been established that public policies are not permanent but are subject to revision, alteration and scrapping if not satisfactory. Apparently, public policies should be consensus opinion of dominant individuals or groups which change when the dominant groups change and lose dominance as other new groups emerge. Therefore, while debatable, this era, may be a good time as any, to scrape the policy which continues to disadvantage and limit African children where it comes to the use of English as the medium of instruction in schools and tertiary institutions.

However, it would be dangerous to take a binary approach and assume that everything western should be abandoned, that the English language should be abandoned in favour of native languages. It also goes without say that the English language has also established its place as the medium of business communication. African people will still need to conduct business transactions with the outside world, which makes it necessary to be able to communicate in that "universal language." In that case, it would probably be necessary to adopt and English for specific purposes (ESP) approach where African students would be compelled to learn only the English that would enable them to function in their area of expertise.

The mere lobbying of a return to the source is marred with problems as the assumption would be that the past is there somewhere in its original form, waiting for people to return to it, which is not the case. This kind of radicalism is a cause for concern as it breeds, dogmatism, which is counter- productive. Flexibility and willingness to adopt positive change are important ingredients to the development of any nation.

However, People of the world at large, should be able to get used to forming with other cultures, relationships based, not on dominance but on co-operation and co-existence. In which case, the English language should be able to operate equally with the native languages, in schools and tertiary institutions.

National educational policies should aim at increasing and strengthening international interaction at all levels, in particular at the higher levels where very often, friendships play a leading role in promoting international relationships. Common responsibilities should in turn form the guiding principles towards international education which builds communication co-operation and confidence, which work towards the development of nations.

An education in which all languages are viewed as equal ensures an appreciation for the cultures of the various people, and respect for the different modes of living, the need for long term joint ventures in each other's physical and social space for the development of all nations.

The solution therefore, probably lies somewhere in the middle, where systems of education, in particular at the tertiary level should allow the flexible use of both the English language and the native languages, instead of limiting the otherwise, excellent student in his or her subject area, on the grounds of him or her not being proficient in the English language, a student, who otherwise would have brought positive change towards development.

\section{Conclusion}

In the end, it becomes apparent that Africans should remain rooted in their traditional structures and spheres in their quest for development. At the same time, they (Africans) should be able to embrace the positive, and also the now inevitable changes that the Western world has brought to Africa. Instead of being blinded by extreme binary relations, for example in this case, whether to go the modernisation theory way or the 
dependency theory way in the quest for development, Africans must learn to adopt a middle of the road approach where they utilise only the positive traits of each of the development models, for the sake of progress.

\section{References}

[1] F. Nemani, Modernisation and Industrialisation Theoretical Framework for the Transition to Industrial Capitalism (London: Penguin, 1997).

[2] W.W. Rostow, The Stage of Economic Growth, a non Communist Manifesto, (Cambridge: Cambridge: University Press, 1960).

[3] V. Ferraro, Dependency Theory: An Introduction (South Hadley: Mount Holyoke College, 1996).

[4] O. Senkel, National Development Policy and External Dependency in Latin America, The Journal of Development Studies, (6), 1969.

[5] F. Salager-Meyer, Hedges and Textual Communicative Function in Medical English Written Discourse, English for Specific Purposes, 13(2), 1994,149- 171.

[6] T. Dos Santos, Readings in U.S Imperialism, In Fann et al (Boston: Porter Sargent1971).

[7] B. Davidson, The Black Man's Burden (Oxford: James Carey, 1992).

[8] B. Blake, All About Language (Oxford: Oxford University Press, 2008).

[9] C.A. Bowers, Cultural Literacy for Freedom (Eugene: Elan Publishers, 1974). 